\title{
DESIGN AND ECONOMIC EVALUATION OF PROGRAMMES INTEGRATING THE STERILE INSECT TECHNIQUE
}

\author{
J. D. MUMFORD \\ Imperial College London, Silwood Park, Ascot, Berkshire SL5 7PY, UK \\ Email: j.mumford@imperial.ac.uk
}

\section{TABLE OF CONTENTS}

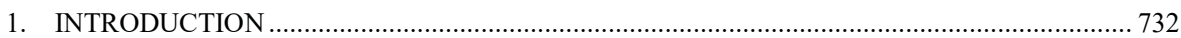

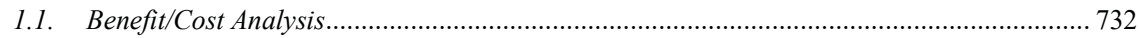

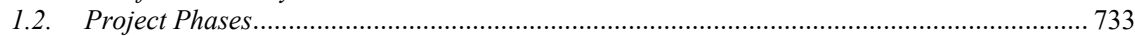

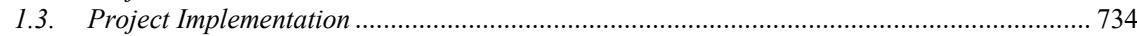

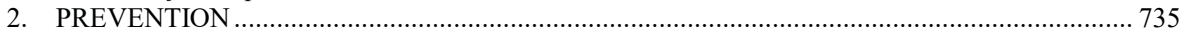

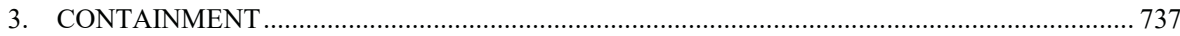

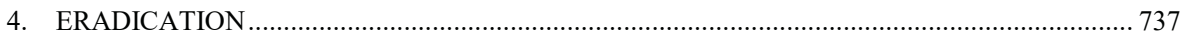

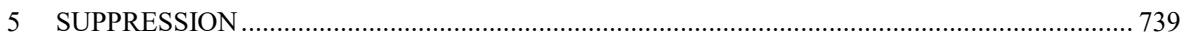

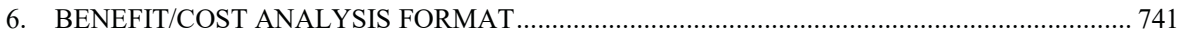

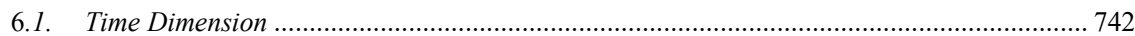

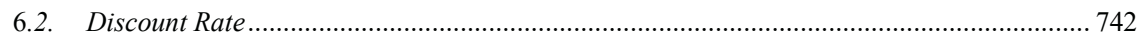

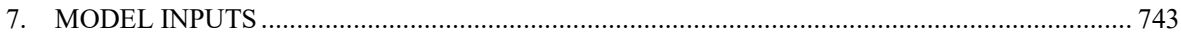

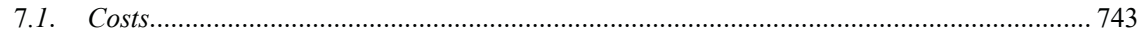

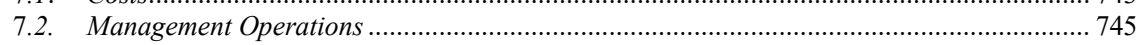

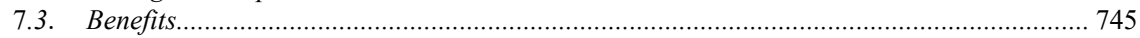

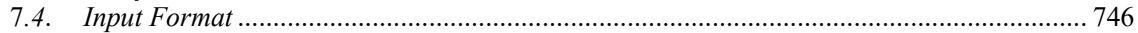

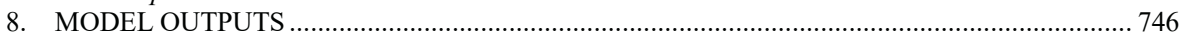

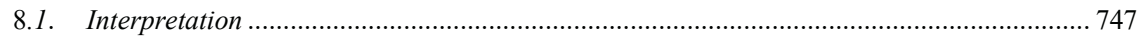

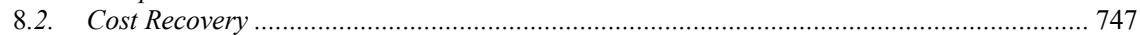

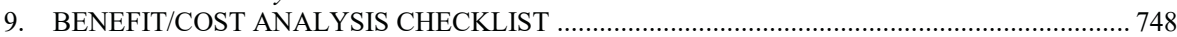

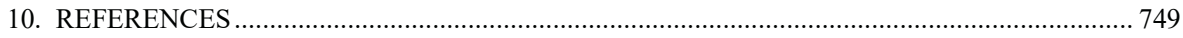




\title{
SUMMARY
}

\begin{abstract}
Area-wide integrated pest management is designed for specific purposes, and an economic evaluation should determine its performance against those purposes. The sterile insect technique is used for eradication, suppression, containment and prevention, each of which has different performance measures. Eradication or suppression of insect pest populations using the sterile insect technique (SIT), together with other area-wide control measures, may require significant initial capital investments to achieve longterm returns in subsequent periods. It may also raise questions about the distribution of benefits or the justification of public or private pest control efforts, given long-term uncertainties about the pest challenge and the potential of new control options. A consistent and transparent evaluation is needed to analyse the benefits and costs of such projects and to demonstrate their value, or in some cases to assess appropriate contributions to the costs by the various stakeholders who gain the benefits. Suppression must be compared with expected losses and costs in alternative conditions without SIT application, either from recent experience prior to implementation of the SIT or with similar areas without SIT treatment. Preventive SIT should reduce the frequency of outbreaks compared with experience prior to the application of the SIT or in similar areas elsewhere without SIT use. This chapter outlines the process of benefit/cost analysis, in which itemized future costs and benefits are compared in terms of present values. It also provides a review and examples of the application of benefit/cost analysis to the SIT. A checklist of benefit/cost analysis inputs and some example benefit/cost outputs are also presented.
\end{abstract}

\section{INTRODUCTION}

The sterile insect technique (SIT) has been used under different circumstances for four purposes: eradication, suppression, containment and prevention (Hendrichs, Vreysen et al., this volume). Eradication has been effective particularly in eliminating new outbreaks in areas with a low probability of reinvasion, or on established populations in isolated areas such as islands (Feldmann et al., this volume). Suppression has been effective for established populations in endemic areas, with buffer zones to limit immigration of mated wild females (Mangan and Bouyer, this volume). Containment has been achieved to avoid the spread of a pest into a free area (Enkerlin, this volume; Vargas-Terán et al., this volume). Prevention has been successful to prevent the establishment of an invasive pest incursion in areas of relatively frequent invasion (Enkerlin, this volume). Economic evaluation of programmes for each of these purposes should focus on indicators of performance relevant to the intended design, and the temporal and spatial scales involved. In each case a form of benefit/cost analysis (BCA) may be appropriate, usually involving probabilistic simulations of scenarios reflecting the pest challenge and control efficacy.

\subsection{Benefit/Cost Analysis}

The principle of a benefit/cost analysis is to provide a model framework in which all costs and benefits applicable to a programme (targeting eradication, suppression, containment or prevention) can be compared with alternative management options over a specified period of time (Kehlenbeck et al. 2012). This is important for comparing area-wide projects integrating the SIT (which generally have substantial initial costs, but which provide long-term benefits, including in some cases eradication) with individual and short-term localized control (such as by conventional pesticide application). The analysis informs decision-making by 
structuring the estimates of all costs and benefits, including externalities such as environmental and social impacts, but it does not prescribe choices. Ultimately, decisions depend on social, political and commercial judgements, and a BCA is a tool for making that decision process more transparent for governments, investors and beneficiaries.

In a BCA the monetary values of all identifiable benefits and costs are estimated as objectively as possible over the expected period during which the project will operate and be effective. Establishing a reasonable estimate of the relevant time horizon in which to judge a programme is a critical step in such an analysis. Because the benefits and costs are in the future, inevitably there is uncertainty in these estimates. A BCA model needs to be flexible so that the various management options and expected scenarios can be tested, taking into account these uncertainties and demonstrating the sources and influence of the uncertainty. For example, Vo (2000) presented two scenarios for an assessment of the New World screwworm Cochliomyia hominivorax (Coquerel) in Jamaica, in which the major uncertainty was programme cost. For some species, e.g. the Mediterranean fruit fly Ceratitis capitata (Wiedemann), rearing costs are well known (IAEA 2008) but there may be considerable uncertainty about other variables, such as reinvasion frequency, which may change with trade patterns or short-term climate variability. For other species that are less commonly mass-reared, such as the codling moth Cydia pomonella (L.), technological improvements can quickly change the costs and effectiveness of reared irradiated insects (Vreysen et al. (2010); Chidawanyika and Terblanche (2011); Parker, Mamai et al., this volume; Simmons et al., this volume). Current small-scale releases of sterile or genetically modified sterile mosquitoes for dengue and Zika management in Brazil (Carvalho et al. 2015) are likely to become much less expensive and more efficient as experience and development continues (Lees et al., this volume). The combination of technological, trade, development and climate change suggests keeping time horizons for a BCA relatively short to avoid levels of uncertainty that could make sound predictions not feasible.

Sensitivity analysis, the process of testing the model with a realistic range of values, is important in benefit/cost analysis to indicate how risks associated with the project could affect decisions. Ideally, the economic framework should be prepared in parallel with the design of technical plans for the project so that each can inform the other. In this way, the final analyses can be efficiently directed to the most effective technical and economically viable plans.

\subsection{Project Phases}

The initial steps in a BCA include defining the timescale and the likely geographic scope of the project. The time period may include: preparatory phases (research, host surveys, baseline data collection, construction of SIT production facilities, etc.), a control phase (which could include a series of zones through which treatments are applied in succession as eradication, suppression, containment or prevention is achieved), and a reasonable period beyond the control stage (long enough for benefits to establish before there is the inevitable time-related increase in uncertainty about reinvasion, new pest entry or other circumstances that could affect the 
expected benefits or costs). The first two phases can be limited by technical constraints, although there may be opportunities to reduce such constraints by spending more money, whereas managerial and political constraints are more difficult but can be overcome by improving managerial capacities, facilitating the organization of grower associations, and establishing public-private partnerships. The geographic scale may also be determined by technical considerations (islands, topography and limit of host range) or by economic factors (too little return in areas of marginal productivity or lower pest attack).

A cost function is likely to be composed of three parts: variable costs per area to be treated for control and variable costs for all other related management activities (surveillance, follow-up treatment, etc.), along with fixed costs associated with operating the project. The benefits would include a function based on replacing current costs and losses in the area to be controlled, plus any additional market opportunities that may arise through low pest prevalence, pest eradication and/or elimination of pesticide residues. Costs and benefits may need to be attributed to particular production sectors or uses, e.g. production of meat, milk and draught power for tsetse fly control (Feldmann et al., this volume), or to geographic areas, e.g. in selection of individual regions where benefits might be greatest. Environmental costs and benefits, discussed later in this chapter, should be included along with direct monetary values from improved production and cost savings. An increasingly important issue in pest management BCAs is how much of the cost can be recovered from stakeholders (in cash or kind), and how this can be achieved (Waage et al. 2007; Dyck, Reyes Flores et al., this volume).

\subsection{Project Implementation}

A BCA may be needed both before and after project implementation, first as a design tool to plan the project, and later to evaluate performance and suggest operational improvements (Pereira et al. 2013). Many eradication and suppression projects have been undertaken or proposed, of which most have had either formal or informal benefit-cost analyses. Enkerlin (this volume) summarizes benefits from a wide range of fruit fly programmes. SIT projects and plans have included: Mediterranean fruit fly (California (Dowell et al. 2000; CDFA 2014; USDA 2014), Florida (USDA 2014), Maghreb (Mumford et al. 1995), Eastern Mediterranean (Enkerlin and Mumford 1997), South Africa (Mumford 1997; Barnes 2007), Portugal (Mumford and Larcher Carvalho 2001), Western Australia (Mumford et al. 2001), Chile (UN 1997), Tunisia (Knight 2001), Argentina (De Longo et al. 2000)), tsetse fly (Kabayo and Feldmann 2000; Msangi et al. 2000; Vreysen et al. 2014; Feldmann et al., this volume), New World screwworms and Old World screwworms Chrysomya bezziana (Villeneuve) (Tweddle and Mahon 2000; Vo 2000; Wyss 2000; Vargas-Terán et al., this volume), codling moth (Canada (Bloem et al. 2000; Simmons et al., this volume), Syria (Mumford and Knight 1996), South Africa (Mumford 1997)), and Aedes mosquitoes (Carvalho et al. 2015; Lees et al., this volume). Cost and general loss estimates for some other fruit fly programmes without an SIT component exist for Egypt (Joomaye et al. 2000), the Indian Ocean 
islands (Price and Seeworoothun 2000) and Pakistan (Stonehouse et al. 1998) for comparison with programmes that integrate SIT management.

The economic conditions that favour an area-wide approach include the integration of efficient and effective techniques such as the SIT, clearly articulated demand by stakeholders, good management capacity (Dyck, Reyes Flores et al., this volume), stakeholder participation, risks that are similar across a broad range of beneficiaries so that economic returns are fairly evenly distributed, a mechanism to capture benefits and recover costs, and, because the SIT is species-specific, it also relies on there being preferably a single dominant pest species (Klassen 2000; Lindquist 2000; Mumford 2000).

\section{PREVENTION}

Prevention of pest establishment using the SIT in pest free areas with a high invasion risk reduces the frequency and cost of outbreaks. It replaces occasional and unpredictable costs with a lower, relatively stable cost of preventive control. It can also reduce the externalities associated with emergency control in a crisis, if widespread pesticide spraying is needed in such a crisis.

The preventive SIT programme against the Mediterranean fruit fly in California is a partnership between the California Food and Agriculture Department and the United States Department of Agriculture. It operates in an area around the Los Angeles basin at a cost of about USD 16 million per year, and has reduced outbreaks from an average of 7.5 per year to less than 1 per year within this area (CDFA 2014). Similar programmes have been run in Florida, with both states using preventive SIT since the mid-1990s. These long-term predictable costs are preferable to relatively frequent and unexpected emergency eradication costs which, together with the temporary loss of exports, can run in extreme cases to over USD 100 million for a single eradication campaign (Box 1)

\section{Box 1. Preventive Release}

This is an example of a comparison of scenarios for preventive SIT release with an alternative form of periodic pest outbreak control. In this example, preventive SIT reduces the annual probability of a pest introduction becoming established to create an outbreak from 0.3 to 0.1 , and the cost of controlling such an outbreak when it does occur from a mean and standard deviation of (USD 50 million, USD 10 million) to a much smaller distribution of costs (mean USD 10 million, standard deviation USD 2 million). In this example preventive SIT has an annual cost of USD 5 million, which would include rearing and release of the sterile insects, monitoring and surveillance, and publicity. The two options can be compared in a series of simulation runs sampled from the probability distributions of outbreaks and costs and a net present value (NPV) cost for each option can be calculated, in this case with a discount rate of 0.03 . Multiple runs would provide a distribution of potential outcomes (based on total costs over ten years) so that a comparison of the two distributions could be made. Fig. 1 illustrates one such run. Because the number and cost of outbreaks are probabilistic, the number and timing of outbreaks would be different in each run. 

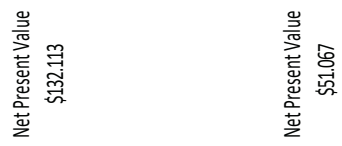

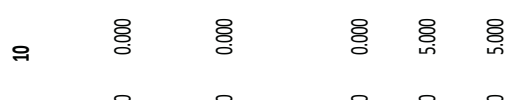

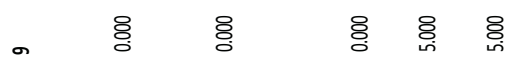

$\infty \times$ 売 売

- \& 8 8 8 8 8

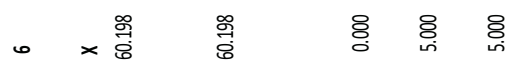

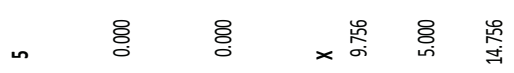

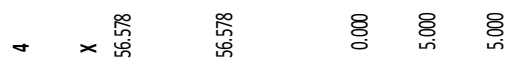

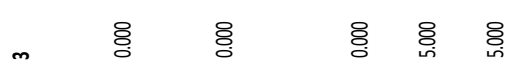

8 8 8 8 8

- 8 8 8 8 8

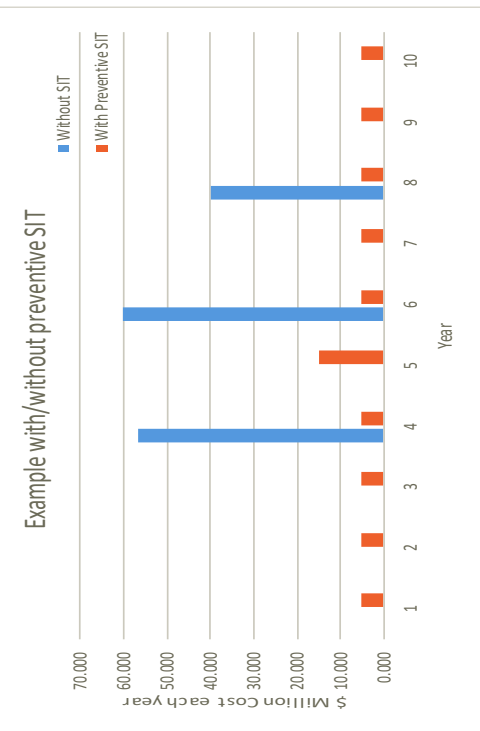

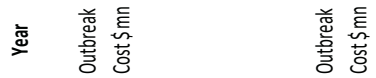

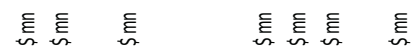

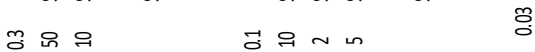

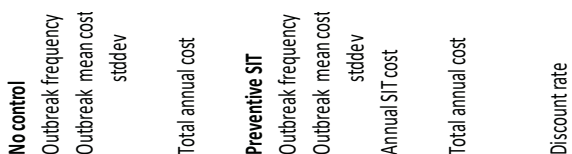

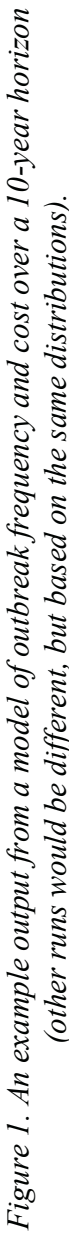




\section{CONTAINMENT}

Releases to establish a sterile-insect barrier across the edge of a potentially advancing pest population can have a containment effect, where they are used to avoid the spread of the pest population into an area free of that pest (Enkerlin, this volume; Vargas-Terán et al., this volume). This is in principle similar to a preventive release programme, but one in which the threat comes mainly from natural spread from an immediately adjacent infested area rather than from introductions through trade or travel from a distant source. The economic value of containment is the trade value retained by being able to demonstrate continued pest free status in the uninfested area and the further value of not needing to apply regular pest control measures for the excluded pest. In several respects the conditions for a containment barrier are different from a preventive release programme. In containment the source, population density, movement and destination of the pest are likely to be well known and occur at relatively high pressure along the boundary between the infested and uninfested areas. For preventive programmes, intermittent unpredictable introductions from a range of sources can occur that are likely to result in dispersed isolated outbreaks over large areas of vulnerable territory, depending on where infested material is taken through human-assisted transport. Containment programmes, therefore, are likely to face greater and more sustained pest pressure, but in relatively well-defined areas.

Containment, by some means, would be a form of official control needed to establish and maintain the status of a pest free area. The containment activities would need to be compatible with the surveillance used to demonstrate pest free status. The width and intensity of the containment zone would be the major determinants of the cost of containment, and the extent to which the containment zone extended into areas which otherwise might enjoy pest free status would limit the benefits.

Successful containment may also have an economic option value, keeping open the potential for a future eradication campaign in the infested area.

\section{ERADICATION}

The benefits of SIT-based eradication have been widely described, and vary enormously with the species concerned and the scale and objective of the project. For example, the potential eradication of tsetse species of economic importance throughout Africa anticipated an overall benefit of USD 4500 million/year (of which USD 1200 million/year is in direct losses from trypanosomiasis affected cattle and associated current control costs (OAU 2000)). Vreysen et al. (2014) indicated higher development potential in areas with effective tsetse control, with the proportion of small-scale farmers keeping indigenous cattle increasing three fold to $94 \%$ after the elimination of tsetse pressure in Zanzibar. Subsequent to eliminating tsetse, the largest benefit to agriculture in the long-term is the opportunity to introduce more productive cattle breeds (Feldmann et al., this volume). On the other hand, in areas with multiple tsetse species, eradication would entail much higher costs and therefore be less economically feasible (Hargrove 2003). Such analyses could also 
be used to set target cost levels for more efficient sterile insect production (Parker, Mamai et al., this volume) and release (Dowell et al., this volume) to achieve returns comparable with conventional control that also has the capacity to achieve eradication.

Very large-scale eradication projections should take into account uncertainties about the continued political will or institutional capability to see a programme through to its final stages to ensure full realization of the benefits, and prevent reinvasion from the remaining uncontrolled areas. Continental-scale eradication integrating the SIT for the New World screwworm in North and Central America has been possible because of the long-term commitment to maintain and extend the SIT control effort.

Mediterranean fruit fly outbreaks in California threaten losses estimated from USD 1000 million/year (IAEA 1999) to USD 1800 million/year (CDFA 2008). The successful eradication of the Mediterranean fruit fly in Chile in 1995 opened up approximately USD 100 million/year in additional fruit markets (IAEA 1999). Enkerlin (this volume) reviews other examples of significant economic benefits from SIT eradication projects (Box 2).

\footnotetext{
Box 2. Eradication

The Mediterranean fruit fly has been a pest of commercial and backyard fruit throughout much of Western Australia since it was introduced to the state around 1900. It imposes costs on fruit growers who use pesticides for control and through both the presence of the insects themselves and the residues from insecticide. Backyard growers also suffer and get less enjoyment from their fruit trees. It also causes problems for the export of Western Australian fruit internationally and to other Australian states. South Australia, in particular, is faced with costs of quarantine and eradication of frequent incursions or outbreaks due to the Mediterranean fruit fly originating from Western Australia.

A pilot project applying the SIT was conducted at Broom, Western Australia, and showed that SITbased eradication of the Mediterranean fruit fly was technically achievable in Australia (Jessup et al., 2007). In an analysis of the feasibility of eradicating this pest in Western Australia (Mumford et al. 2001), it was clear that eradication would take several years in a series of geographical zones. The model was based on a concept of summing the individual costs and benefits across each zone, allowing for a phased extension of the eradication across the state with a rolling quarantine to protect the eradication frontier as it progressed. The principal inputs within each zone affecting costs and benefits were the total areas to be treated and the values of losses that would be prevented with eradication. The zone boundaries were selected based on:

- climate (related to the threat from the Mediterranean fruit fly, mainly the effect of winter temperature)

- a phased increase in the treated area to build up expertise and capacity

- treatment areas were determined by satellite imagery of likely host presence and agricultural census data

- a maximum annual area to treat of $1000 \mathrm{~km}^{2}$ (reflecting managerial capacity)

- a phased decrease in treated area as the programme winds down through lower risk areas to maintain capacity in the event of renewed outbreaks in any fly-free areas

- existing local government administrative districts to be used as the basis of both statistics and management.
} 


\section{SUPPRESSION}

On a much smaller scale, in South Africa grape growers on 4000 hectares in the Hex River Valley were predicted to save over USD 150 per hectare per year in conventional insecticide costs, plus the added value of entering low-residue markets, through using the SIT for Mediterranean fruit fly suppression (Mumford 1997). Subsequent results showed control costs falling from USD 350000 to USD 130000 as the SIT replaced most chemical control, and market rejections due to fruit flies were reduced by half (Enkerlin, this volume). While pesticide reduction was not as great as expected, it was still substantial, and illustrates the uncertainties involved in making estimates. Permanent suppression integrating the SIT, rather than targeting eradication, offers advantages for Mediterranean fruit fly control in countries around the Mediterranean where nearby endemic pest populations would result in continual reinfestation and the cost of effective quarantine would be prohibitively high. While suppression does not have the finality that gives eradication such political appeal, it does not have such high costs of certification and quarantine (Mangan and Bouyer, this volume). Furthermore, because there would be an ongoing need for sterile insects, there may be greater potential interest for private investment in sterile insect production facilities and delivery services (Mumford 2000; IAEA 2008). Continued benefit from reduced pesticide use can offer a steady and attractive market for efficient SIT suppression.

The integration of sterile or genetically modified mosquitoes for suppression of vectors is a new development for the SIT, aimed at more effective control than can be achieved by only applying insecticides or removing breeding sites. Outbreaks of dengue can occur at very low densities of Aedes mosquitoes, and control methods with inverse density-dependent performance such as the SIT are more economically efficient in such low-density populations, or after other vector populations have been suppressed by conventional means (Pereira et al. 2013; Häcker et al., this volume; Lees et al., this volume; Mangan and Bouyer, this volume). Effective suppression of vectors may in some cases be sufficient to eliminate a disease in an area, if the vector population can be reduced to a density that does not sustain transmission (Smith et al. 2012).

For a practical decision on the merits of SIT eradication or suppression, the benefits must be set against expected costs, which for many projects integrating the SIT are now well-documented in a range of national circumstances. Issues remain, however, around how to capture the benefits within the various economic sectors that gain from control, and to transfer some of this to the public or cooperative sectors that provide the service. SIT projects have traditionally been public projects, but may increasingly be partly or wholly funded directly by beneficiaries. Payment for the SIT as a service by direct beneficiaries is more likely where ongoing inputs are involved (suppression and prevention) to give relatively immediate returns to those paying for the service (Dyck, Reyes Flores et al., this volume). Because eradication gives benefits in the future, and requires external efforts to prevent reinvasion, it is likely to be less attractive to private subscribers (Box 3). 


\begin{abstract}
Box 3. Suppression
Scenarios for suppression can be designed on a spatial grid that considers the costs and benefits per cell each year. The example below, from the CLEANFRUIT project funded by the European Commission (J. D. Mumford and A. W. Leach, unpublished; CLEANFRUIT 2017), illustrates an example of a scenario for a Mediterranean fruit fly suppression programme in Croatia. Each $1-\mathrm{km}^{2}$ cell on the map has a number indicating the density of citrus production in the cell, which is an indicator of the potential benefit from SIT suppression. Buffer zones are indicated near any cell with a sufficient density of citrus to trigger the need for a buffer. All citrus, urban and buffer cells have a standard cost function for the SIT inputs needed for a cell area of that size. Annual costs and benefits can then be estimated for any scenario in a potential programme design, supporting decisions on where to draw programme boundaries and how to allocate public or subscription costs. For example, private subscriptions may be based on specific cell benefits and public subsidy based on average cell costs.
\end{abstract}

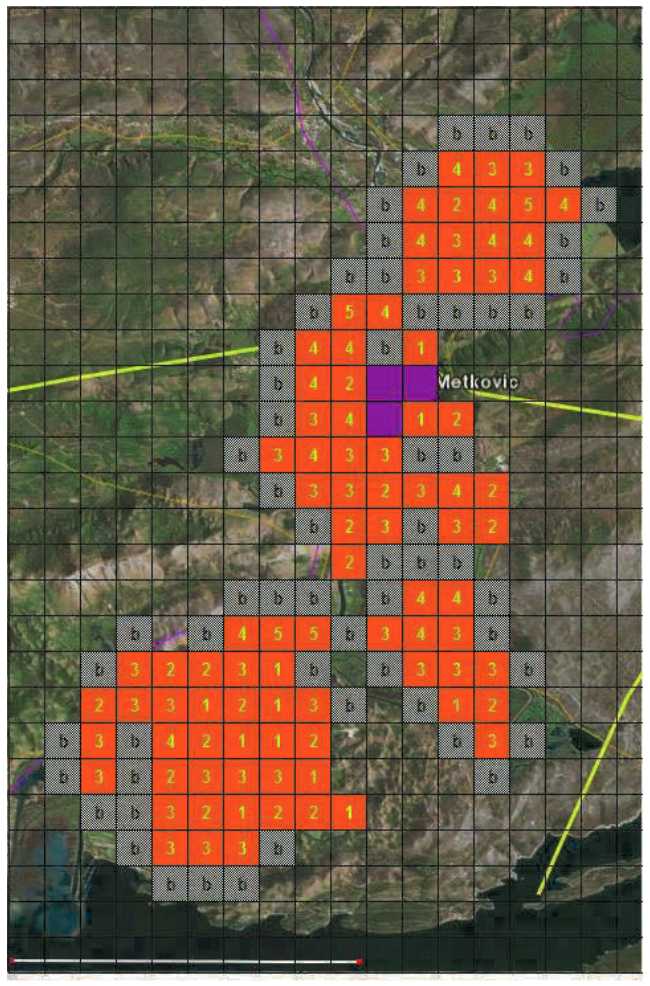

1) Enter a value between 1 and 10 to indicate the cover of orchards within each $1 \times 1 \mathrm{~km}$ cell e.g. $1=10 \%, 5=50 \%$ \& $10=100 \%$ of orchard cover etc

2) Enter "u" in a cell for urban areas

\begin{tabular}{|c|c|}
\hline Country name & Croatia \\
\hline Zone name & Neretva Valley \\
\hline Orchard area $\left(\mathrm{km}^{2}\right)$ & $25.4 \mathrm{~km}^{2}$ \\
\hline Buffer area $(\mathrm{km} 2)$ & $17 \mathrm{~km}^{2}$ \\
\hline Urban area $\left(\mathrm{km}^{2}\right)$ & $3 \mathrm{~km}^{2}$ \\
\hline Other host area $\left(\mathrm{km}^{2}\right)$ & $0 \mathrm{~km}^{2}$ \\
\hline Non host area $\left(\mathrm{km}^{2}\right)$ & $107.2 \mathrm{~km}^{2}$ \\
\hline Total Area $\left(\mathrm{km}^{2}\right)$ & $153 \mathrm{~km}^{2}$ \\
\hline Urban \& Other host: Orchard Area Ratio & 0.00 \\
\hline
\end{tabular}

Buffer neighbour trigger

Width (m)

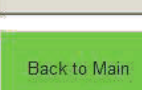




\section{BENEFIT/COST ANALYSIS FORMAT}

The output of a BCA is likely to appear as a time profile indicating inputs and outputs by year, location and sector (which could be crop/livestock/human health type, urban/rural, public/private, etc.) depending on the needs of the commissioning agency. A scenario for a programme outlines the conditions for the modelled flows of inputs and benefits as each area reaches the stage assigned for particular management actions. An example of output flow of benefits minus costs appears in Fig. 2, illustrating the time flow of outcomes in an eradication plan.

The model structure has a set of cost and benefit components, specified as a probability distribution for each area and each year. Each of these refers to a standard set of cost, price and production parameters (with associated uncertainties) per area to give the model consistency while allowing the flexibility to analyse different SIT management plans. Different plans could, for instance, include changing the sequence of zones to be controlled, or the number or size of zones eradicated in each year. Values would be expressed with specified levels of uncertainty associated with them. For example, the cost of sterile flies may not be known before a factory is built, but costs from similar factories give a good approximation. Sensitivity analysis would demonstrate the range of outcomes using input values with some variation around the most likely expected values.

Many of the BCA models referred to in this chapter are related to the general format of a generic Mediterranean fruit fly BCA model developed for the IAEA (FAO/IAEA 2007). While each case has specific elements of geography, ecology or market conditions, there are many common principles and a growing globalization of SIT infrastructure. For example, large and efficient production facilities (IAEA 2008) can ship sterile insects to an international market at competitive prices: New World screwworms from Mexico to Libya, and Mediterranean fruit flies from Guatemala to the USA, Israel and South Africa, Spain to Morocco, and Israel to Croatia. Many items of equipment used in rearing and aerial release are now common across many projects. Many components of costs for sterile insects and their application are therefore fairly standard throughout the world, and common tables of such costs and standard application procedures help in planning both publicly and privately financed SIT efforts. However, as noted earlier, costs are not so stable for many species other than the Mediterranean fruit fly. Labour costs vary from country to country, but automated systems can reduce some of these costs. 


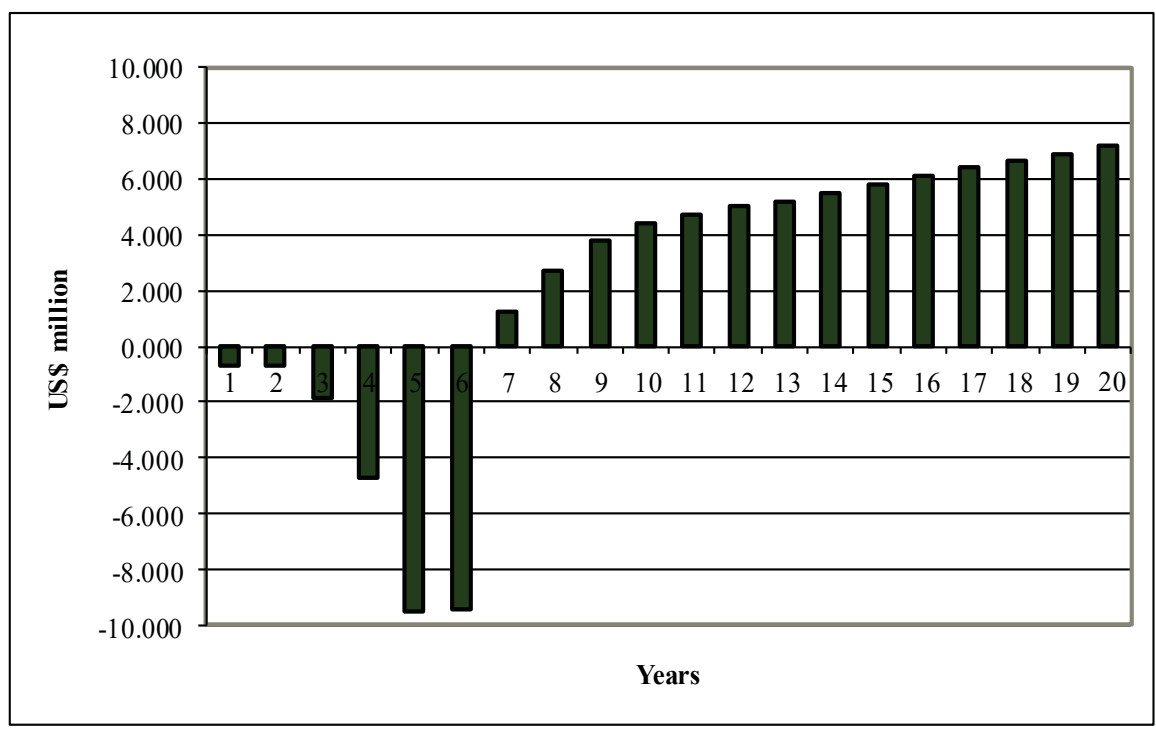

Figure 2. Annual net projected benefit-cost for one scenario of the Western Australia Mediterranean fruit fly eradication plan before any discount rate was applied (Mumford et al. 2001).

\subsection{Time Dimension}

The time dimension for BCA predictions is very important, since there is a trade-off between adding the extra benefits over a longer term after most of the cost has been completed and adding greater uncertainty of further pest invasion, market changes, etc. While eradication may be seen by many as a once and for all achievement with an indefinite stream of benefits, experience shows that reinvasion may occur frequently in some areas of high risk of incursions (for example, the Mediterranean fruit fly has recurred in California and Florida following eradications, although the benefits of even short-term eradication exceeded the costs in such major exporting areas). So, while longer time frames would give a greater apparent return to an eradication programme, assuming the costs of maintaining quarantine or preventive control are not prohibitive, the probability of losing the benefits through a new outbreak increases as more years are added to the anticipated flow. In any event, future discounting reduces the impact of extending the time horizon.

\subsection{Discount Rate}

Benefits and costs that arise in future years should be compared in terms of their equivalent present values so that all the values are directly comparable, since the same nominal value further in the future is worth less in present terms. The net benefit (benefit minus cost) over the whole project period being considered would 
be expressed as a net present value. The discount rate is used to calculate these present values. The discount rate is a measure of the value that people place on having money now rather than later. It is generally considered to be equal to the interest rate on savings minus the inflation rate, both of which are currently at very low levels in developed economies. At present, in relatively stable economies, the discount rate ranges from about $1-4 \%$, with the US government guideline on discount rate suggesting a central value of $2.9 \%$ for public benefit projects with a time period of 10 years (OMB 2015). However, it is likely to be higher in less stable economies (Mumford 2000). While a common discount rate, such as $5 \%$, could be used in all analyses, this would not demonstrate the differences in future values that actually occur in different economies. To calculate present value, the following formula is used:

$$
\text { Present value }=\text { Future value } /\left((1+\text { Discount rate })^{\text {Years }}\right)
$$

At a discount rate of $0.05(5 \%)$ this formula indicates that a value of USD 100 in 10 years has a present value of only USD 61, and USD 100 in 20 years is worth only USD 38 in present terms. Therefore, long time frames do not add as much benefit as may be imagined, particularly where discount rates are high, while they add greatly to the uncertainty of the estimates. Because discount rates now used by many governments are much lower than they were in the past, the net present value of area-wide insect control over ten-year periods will be much greater than it would have been in previous decades, when much higher discount rates prevailed.

\section{MODEL INPUTS}

\subsection{Costs}

The following cost items need to be predicted:

- Pest management treatments (the combination of the SIT and related technologies to be applied based on technical selection and specification of control activities and locations; variable costs to be determined per unit area, plus initial and subsequent annual fixed costs)

- Management area (this is the main driver for costs because most costs are variables based on treatment application per unit area; also consider if particular areas have additional needs that affect costs, due to terrain, remoteness, etc.)

- Cost categories (examples are given for some of the important cost categories, mainly based on values for the Mediterranean fruit fly, one of the most commonly controlled pests using the SIT, but some of the categories are too sitespecific to give meaningful examples)

- Pre-treatment preparation (baseline data collection, demonstrations, trials to prove the effectiveness of techniques, and to build technical capacity and public confidence)

- Surveys (pest population, host areas, current control practices and losses) 
- Population reduction needed prior to the SIT (by bait or other treatment) to bring populations to a low enough density for effective SIT control (Mangan and Bouyer, this volume)

- For the Mediterranean fruit fly, approximately USD 6000 per km² (Mumford et al. 2001)

- Environmental costs (mainly pesticides used for pre-SIT population reduction):

○ Leach and Mumford (2008) proposed a Pesticide Environmental Accounting value for pesticides which gives an economic value for the environmental damage for many individual pesticides, particularly those used in horticulture. The environmental values are very variable depending on the particular pesticide properties.

- Environmental and health impacts can also be quantified in monetary units using willingness-to-pay methods or by establishing aspiration levels (Farnsworth 1986; Nagel and Peveling, this volume).

- SIT costs:

○ Production, for the Mediterranean fruit fly, approximately USD 250-500 per million irradiated male pupae at the factory (rate of release would be $100000-150000$ per $\mathrm{km}^{2}$ per week, numbers may depend on host density) (IAEA 2008)

- Delivery, reception and release actions are described in detail in FAO/IAEA (2017) (Dowell et al., this volume)

- Costs are highly dependent on the proximity of the production facility to release points.

- Aerial release costs depend on the type of aircraft and the numbers released; ground release is only practical for small areas.

- Quarantine (prevention of re-entry and management of outbreaks posteradication)

- Monitoring (during and post-eradication) and certification (intensive monitoring post-eradication to prove pest free status) (Barclay et al., this volume; Vreysen, this volume)

- For the Mediterranean fruit fly, a certification trap grid of 10 per $\mathrm{km}^{2}$ inspected fortnightly at USD 2-3 per inspection (Mumford et al. 2001); monitoring during control may be less, e.g. 4 traps per $\mathrm{km}^{2}$ in the preventive release programme in California (Dowell et al. 2000).

- Miscellaneous costs (administration, public awareness, marketing the improved pest free quality of produce from the area)

- Additional management and infrastructure costs to cope with possible increased pressure on land use after pests are eliminated.

Also needed - a time profile of the inputs, with changes over time, a time limit for analysis and an agreed discount rate. 


\subsection{Management Operations}

The management operations are specified according to the technical needs of the project, for example pre-SIT bait applications. The economic analysis can be used to choose between different technical options, e.g. the order in which zones are treated in a phased eradication may have significant economic implications. There may be technical or managerial limits on the size of treatment zones, which affects the pace of eradication. The release rate of sterile insects, pre-SIT control regimes and standards for monitoring are all based on previous experience in successful eradication projects and the ecological circumstances in the area, or for new SIT species on field research in pilot projects.

The treatment area in each year consists of all of the pest-host area within a zone, along with some additional areas along the edges of host areas, which may result in the infilling of heterogeneous areas depending on the distribution of hosts. The areas may be predicted by land-use images from satellite or aerial photos, and/or from ground surveys. Crop areas, livestock densities and production levels are often available from agricultural statistics, and households can be obtained from census records. Local surveys of vegetation, animals and households may be needed where information is scarce.

Prior to applying SIT treatments there may be a need for trial runs to practise procedures, or to provide some stakeholders with demonstrations of operations and impacts. All subsequent operations can be treated as either direct area functions in a BCA spreadsheet, or as indirect area functions (for instance, environmental costs are likely to be determined by the volume or value of pesticide used, which will itself be area-related).

The timescale for the analysis should include the preparatory phase, the operational phase, and the ongoing period during which benefits and any further costs can be confidently expected to accrue. The endpoint for the analysis should be chosen after consideration of ecological, market and quarantine uncertainties, which increase over time, and the effect of future discounting, which makes long-term future values relatively less significant in present terms.

\subsection{Benefits}

The following groups of benefits are likely to accrue:

- Reduced direct and indirect costs of current control (this requires technical specification and information on the proportion of users for each current practice, obtained by survey)

- Reduced residual losses to crops or livestock, and reduced disease transmission, due to target pests which an SIT treatment would eliminate (such losses may exist despite current control efforts, either because little or no control is applied in many low-input farms, or because control is often not completely effective even when fully applied). The lack of fully effective controls is often a substantial motivation for an SIT treatment, whether targeting suppression or eradication. 
- For livestock, reduced veterinary, surveillance and treatment costs, and faster time for animals to reach sale weight

- Pest control reduces losses because pest attack lowers resistance and increases susceptibility to further insect and disease attack

- Reduced environmental impact from pests that affect natural vegetation or wildlife, which control would prevent. Mumford (2001) describes the ways in which economic values can be put on non-crop losses in natural environments.

- New market opportunities or improved retention of existing markets, e.g. due to reduced pesticide residues on produce or certified disease or insect free status

- Additional development potential in areas under effective pest management, e.g. see Vreysen et al. (2014)

- Greater impetus to invest in agriculture in areas in which pests have been controlled.

A time profile of benefits and their distribution (geographical, sectors, etc.) would be needed, along the same lines as for costs.

\subsection{Input Format}

A typical spreadsheet for a BCA would consist of the following example data pages: a delineation of areas; a catalogue of data on $\mathrm{km}^{2}$ per district (total area and area for particular pest hosts, or density of hosts); SIT treatment areas by zone (excluding areas the target pest would not inhabit due to a lack of hosts or to climatic conditions); potential and residual losses due to the pest (affected by productivity in the area, climate and susceptibility of hosts to pest); current control costs, including social and environmental costs of current control practices, lost market opportunities (due to residues, residual pest damage or quarantine exclusion), SIT treatment costs, including additional monitoring and quarantine costs and pre-treatment preparation, and a discount rate for the country; and the input summaries for each of the scenarios being compared.

\section{MODEL OUTPUTS}

Model outputs should indicate: summaries of costs and benefits over a time line agreed for the analysis of the scenario, and economic indicators (such as net present value, payback period, and internal rate of return) for each proposed scenario. The net present value is the sum of the present values of future net returns, using the discount rate to calculate back to the present from the expected future nominal values. The payback period is the number of years before the cumulative benefits exceed the cumulative costs, which is a measure of the riskiness of a project. The internal rate of return is the discount rate that would give a net present value of zero to the stream of net benefits from the project. The project would exceed the breakeven point if actual discount rates are expected to be below this value. 


\subsection{Interpretation}

The output of the BCA provides a comparison of the stream of net benefits, expressed in present values. Scenarios with higher net present values are preferred, although sensitivity analysis may indicate that some high returns are associated with greater risk. Eradication requires a long-term commitment to ensure the investment in eradication is protected, and this can add considerable cost. The net present value displayed is calculated using the average of each input value, but each of these inputs may be uncertain. Where probability ranges have been estimated for various input values it is possible to use simulation software such as @ Risk $^{\mathrm{TM}}$ to calculate the range and frequencies of output values.

The distribution of benefits can be apportioned by sector (e.g. commercial versus backyard), by geographical zone, by public/private finance, etc. This has important implications for the political desirability of a project, the relative role of various stakeholders and the potential for cost recovery. The initial benefits are likely to go to commercial producers for projects involving fruit flies, codling moths or other agricultural pests. Consumers may subsequently benefit from lower prices if production becomes more efficient later. Also, inhabitants in an area with lower insecticide use will benefit, justifying their financial support to an SIT project (Cartier 2014; Dyck, Reyes-Flores et al., this volume; Simmons et al., this volume).

\subsection{Cost Recovery}

Many countries now have policies that require government to seek to recover costs, wherever possible, from public projects such as insect eradication (Waage et al. 2007). A BCA could form the basis for determining not only what expenditure will be needed for a successful project but, through the assessment of the benefits, how that expenditure should be shared. However, identifying benefits does not directly indicate who should pay. Some costs, for instance non-monetary environmental costs, are difficult to recover, and may only be practical for society as a whole to bear or to claim compensation from government (Mumford 2001). In other cases, many beneficiaries may be involved, making it difficult to collect voluntary payments for area-wide control individually, e.g. when urban householders benefit. In such cases collective payments are more efficiently made, as in the Sterile Insect Release Program in Canada, which has been supported partially by urban residents (through property taxes) for more than 20 years (Cartier 2014; OKSIR 2020; Dyck, Reyes-Flores et al., this volume; Simmons at al., this volume). Such support may need the mandate of a local referendum, or election, for it to be imposed on all those required to pay.

Any area-wide integrated pest management programme (AW-IPM) will encounter the issue of free-riders who do not contribute directly (Lindquist 2000). Where these benefits contribute to the broader public good it may be more efficient to fund projects centrally from government and spread the cost through general taxation. Where the benefits are geographically isolated and beneficiaries are few in number and well-organized, such as in the Hex River Valley Mediterranean fruit fly control project in the South African table grape industry (Barnes 2007), a levy on 
growers or a cooperative subscription system is a practical and fair way to pay for part of the costs. In Brazil, the city of Piracicaba has contracted a commercial supplier to rear and release sterile Aedes mosquitoes in a municipal vector control programme (Le Page 2016), along with enforcement efforts to reduce mosquito breeding sites.

\section{BENEFIT/COST ANALYSIS CHECKLIST}

The following bullet points provide a checklist for decisions on benefits and costs; further examples related to control by more general means can be seen in Kehlenbeck et al. (2012):

- Planning and feasibility studies (technical and economic) that provide initial descriptions of inputs, and estimates of costs and effectiveness

- Current losses due to pests (without control and even with control, for crops or livestock over several seasons) or disease transmission by insect vectors

- Market exclusion due to pest presence, damage or pesticide residues

- Current control practices (area treated, effectiveness, cost, environmental impact)

- Area to be treated overall, including necessary buffer areas beyond infested host areas to prevent reinvasion

- Area within the overall treatment area that contains non-productive land

- Pre-project baseline data collection and monitoring for hosts and populations

- Publicity to make the public aware of an area-wide programme (Dyck, Regidor Fernández et al., this volume)

- Regulatory controls (such as hygiene, local quarantine inspections, reporting of pest occurrence)

- SIT costs:

○ Pre-release insecticide baiting (or alternative population reduction practices)

- Sterile insect production (Parker, Mamai et al., this volume)

- Sterile insect storage and transport

- Sterile insect release (Dowell et al., this volume)

- Field monitoring (for operational management) (Vreysen, this volume)

- Field monitoring for pest free certification (Barclay et al., this volume; Vreysen, this volume)

- Post-control area quarantine

- Marketing to capture benefits of pest and pesticide reduction/elimination

- Additional development potential in controlled areas with effective pest management

- Agreed project timescale and applicable discount rates.

This checklist provides guidelines on the basic information that would ideally be used in a BCA. More precise information will give more confidence in the analysis, but may be expensive to obtain. Therefore, some compromises between uncertainty and cost may be required. The goal is to provide transparent comparisons of specified scenarios with as much objectively agreed information as possible, with any uncertainties explicitly identified and included. 


\section{REFERENCES}

Barnes, B. N. 2007. Privatizing the SIT: a conflict between business and technology?, pp. 449-456. In M. J. B. Vreysen, A. S. Robinson and J. Hendrichs (eds.), Area-wide control of insect pests. From research to field implementation. Springer, Dordrecht, The Netherlands. http://www-naweb.iaea.org/nafa/ipc/public/Area-Wide-Control-Insect-Pests-book.pdf

Bloem, S., K. A. Bloem, and C. A. Calkins. 2000. Incorporation of diapause into codling moth mass rearing: production advantages and insect quality issues, pp. 329-336. In K. H. Tan (ed.), Proceedings: Area-Wide Control of Fruit Flies and Other Insect Pests. International Conference on Area-Wide Control of Insect Pests, and the $5^{\text {th }}$ International Symposium on Fruit Flies of Economic Importance, 28 May-5 June 1998, Penang, Malaysia. Penerbit Universiti Sains Malaysia, Pulau Pinang, Malaysia. http://www-naweb.iaea.org/nafa/ipc/public/Area-wide-control_230-350.pdf

Cartier, L. 2014. A benefit-cost analysis of the Okanagan Kootenay Sterile Insect Release Program. Okanagan Kootenay Sterile Insect Release Program, B. C., Canada. 26 pp. http://library-1.okanagan.bc.ca/vwebv/ocir/SIR_B_C_Analysis_Report.pdf

Carvalho, D. O., A. R. McKemey, L. Garziera, R. Lacroix, C. A. Donnelly, L. Alphey, A. Malavasi, and M. L. Capurro. 2015. Suppression of a field population of Aedes aegypti in Brazil by sustained release of transgenic male mosquitoes. PLoS Neglected Tropical Diseases 9(7): e0003864. DOI:10.1371/journal.pntd.0003864 https://doi.org/10.1371/journal.pntd.0003864

(CDFA) California Department of Food and Agriculture. 2008. Mediterranean fruit fly fact sheet. https://www.cdfa.ca.gov/plant/factsheets/MedFlyFactSheet.pdf

(CDFA) California Department of Food and Agriculture. 2014. Mediterranean Fruit Fly Preventive Release Program. https:/www.cdfa.ca.gov/plant/pdep/prpinfo/

Chidawanyika, F., and J. S. Terblanche. 2011. Costs and benefits of thermal acclimation for codling moth, Cydia pomonella (Lepidoptera: Tortricidae): implications for pest control and the sterile insect release programme. Evolutionary Applications 4: 534-544. http://onlinelibrary.wiley.com/doi/10.1111/j.1752-4571.2010.00168.x/abstract

CLEANFRUIT. 2017. European Commission project CLEANFRUIT in Croatia. EC Framework 6 research project. Identification Number 506495. Final report. http://cordis.europa.eu/publication/rcn/12704_en.html

De Longo, O., A. Colombo, P. Gomez-Riera, and A. Bartolucci. 2000. The use of massive SIT for the control of Medfly, Ceratitis capitata (Wied.), Strain SEIB 6-96, in Mendoza, Argentina, pp. 351360. In K. H. Tan (ed.), Proceedings: Area-Wide Control of Fruit Flies and Other Insect Pests. International Conference on Area-Wide Control of Insect Pests, and the $5^{\text {th }}$ International Symposium on Fruit Flies of Economic Importance, 28 May-5 June 1998, Penang, Malaysia. Penerbit Universiti Sains Malaysia, Pulau Pinang, Malaysia. http://www-naweb.iaea.org/nafa/ipc/public/Area-wide-control_351-490.pdf

Dowell, R. V., I. A. Siddiqi, F. Meyer, and E. L. Spaugy. 2000. Mediterranean fruit fly preventative release programme in Southern California, pp. 369-376. In K. H. Tan (ed.), Proceedings: Area-Wide Control of Fruit Flies and Other Insect Pests. International Conference on Area-Wide Control of Insect Pests, and the $5^{\text {th }}$ International Symposium on Fruit Flies of Economic Importance, 28 May-5 June 1998, Penang, Malaysia. Penerbit Universiti Sains Malaysia, Pulau Pinang, Malaysia. http://www-naweb.iaea.org/nafa/ipc/public/Area-wide-control_351-490.pdf

Enkerlin, W., and J. Mumford. 1997. Economic evaluation of three alternative methods for control of the Mediterranean fruit fly (Diptera: Tephritidae) in Israel, Palestine Territories, and Jordan. Journal of Economic Entomology 90: 1066-1072.

https://doi.org/10.1093/jee/90.5.1066

(FAO/IAEA) Food and Agriculture Organization of the United Nations/International Atomic Energy Agency. 2007. CD-ROM (software and manual): Benefit-cost analysis model: Economic decision tool for area-wide fruit fly management (PC/4930). Joint FAO/IAEA Programme, Nuclear Techniques in Food and Agriculture, IAEA, Vienna, Austria. [A. W. Leach, J. D. Mumford and W. R. Enkerlin]

(FAO/IAEA) Food and Agriculture Organization of the United Nations/International Atomic Energy Agency. 2017. Guideline for packing, shipping, holding and release of sterile flies in area- 
wide fruit fly control programmes, $2^{\text {nd }}$ edn. J. L. Zavala-López and W. R. Enkerlin (eds.). Food and Agriculture Organization of the United Nations, Rome, Italy. 155 pp.

http://www-naweb.iaea.org/nafa/ipc/public/Guideline-for-Packing-Sept2017.pdf

Farnsworth, R. L. 1986. An economic model to measure costs and benefits of eradication, pp. 67-78. In M. Mangel, J. R. Carey and R. E. Plant (eds.), Proceedings: Pest Control: Operations and Systems Analysis in Fruit Fly Management. NATO Advanced Workshop, 5-9 August 1985, Bad Windsheim, Germany. Springer-Verlag, Berlin, Germany.

Fisher, K., R. Bleakley, and N. Thompson. 1994. A benefit cost analysis of the proposal to eradicate Mediterranean fruit fly from Western Australia. Department of Agriculture, Western Australia. 51 pp.

Hargrove, J. W. 2003. Tsetse eradication: sufficiency, necessity and desirability. Research Report, DFID Animal Health Programme, Centre for Tropical Veterinary Medicine, University of Edinburgh, UK. 134 pp.

(IAEA) International Atomic Energy Agency. 2008. Model business plan for a sterile insect production facility. IAEA-MBP. IAEA, Vienna, Austria. http://www-naweb.iaea.org/nafa/ipc/public/IAEA-MBP_SP_facility.pdf

Jessup, A. J., B. Dominiak, B. Woods, C. P. F. De Lima, A.Tomkins, and C. J. Smallridge. 2007. Area-wide management of fruit flies in Australia, pp. 685-697. In M. J. B. Vreysen, A. S. Robinson and J. Hendrichs (eds.), Area-wide control of insect pests. From research to field implementation. Springer, Dordrecht, The Netherlands. http://www-naweb.iaea.org/nafa/ipc/public/Area-Wide-Control-Insect-Pests-book.pdf

Joomaye, A., J. D. Knight, and W. Routhier. 2000. Evaluation of the peach fruit fly problem in Egypt with recommendations for its control and eradication including a limited cost-benefit analysis. C3INT/0/069 13 01, Joint FAO/IAEA Division, Vienna, Austria. 30 pp.

Kabayo, J. P., and U. Feldmann. 2000. Potential for area-wide control or eradication of tsetse flies in Africa, pp. 75-78. In K. H. Tan (ed.), Proceedings: Area-Wide Control of Fruit Flies and Other Insect Pests. International Conference on Area-Wide Control of Insect Pests, and the $5^{\text {th }}$ International Symposium on Fruit Flies of Economic Importance, 28 May-5 June 1998, Penang, Malaysia. Penerbit Universiti Sains Malaysia, Pulau Pinang, Malaysia.

http://www-naweb.iaea.org/nafa/ipc/public/Area-wide-control_73-229.pdf

Kehlenbeck, H., R. Cannon, A. Breukers, A. Battisti, A. Leach, J. Mumford, and A. MacLeod. 2012. A protocol for analysing the costs and benefits of phytosanitary measures. EPPO Bulletin 42 : $81-88$. http://onlinelibrary.wiley.com/doi/10.1111/j.1365-2338.2011.02524.x/abstract

Klassen, W. 2000. Area-wide approaches to insect pest management: History and lessons, pp, 21-38. In K. H. Tan (ed.), Proceedings: Area-Wide Control of Fruit Flies and Other Insect Pests. International Conference on Area-Wide Control of Insect Pests, and the $5^{\text {th }}$ International Symposium on Fruit Flies of Economic Importance, 28 May-5 June 1998, Penang, Malaysia. Penerbit Universiti Sains Malaysia, Pulau Pinang, Malaysia.

http://www-naweb.iaea.org/nafa/ipc/public/Area-wide-control_1-72-Front-Cover.pdf

Knight, J. D. 2001. Cost/benefit economic analysis of SIT for controlling medfly in the Cap Bon area. C3-TUN/5/020-03 01, Joint FAO/IAEA Division, IAEA, Vienna, Austria. 33 pp.

Leach, A. W., and J. D. Mumford. 2008. Pesticide Environmental Accounting: a method for assessing the external costs of individual pesticide applications. Environmental Pollution 151: 139-147. DOI: $10.1016 /$ j.envpol.2007.02.019 http://europepmc.org/abstract/med/17604888

Le Page, M. 2016. First evidence that GM mosquitoes reduce disease. New Scientist, 15 July 2016. https:/www.newscientist.com/article/2097653-first-evidence-that-gm-mosquitoes-reduce-disease/

Lindquist, D. A. 2000. Pest management strategies: Area-wide and conventional, pp. 13-19. In K. H. Tan (ed.), Proceedings: Area-Wide Control of Fruit Flies and Other Insect Pests. International Conference on Area-Wide Control of Insect Pests, and the $5^{\text {th }}$ International Symposium on Fruit Flies of Economic Importance, 28 May-5 June 1998, Penang, Malaysia. Penerbit Universiti Sains Malaysia, Pulau Pinang, Malaysia. http://www-naweb.iaea.org/nafa/ipc/public/Area-wide-control_1-72-Front-Cover.pdf

Msangi, A. R., K. M. Saleh, N. Kiwia, I. I. Malele, W. A. Mussa, F. Mramba, K. G. Juma, V. A. Dyck, M. J. B. Vreysen, A. G. Parker, U. Feldmann, Z. R. Zhu, and H. Pan. 2000. Success in Zanzibar: Eradication of tsetse, pp. 57-66. In K. H. Tan (ed.), Proceedings: Area-Wide Control of Fruit Flies and Other Insect Pests. International Conference on Area-Wide Control of Insect Pests, 
and the $5^{\text {th }}$ International Symposium on Fruit Flies of Economic Importance, 28 May-5 June 1998, Penang, Malaysia. Penerbit Universiti Sains Malaysia, Pulau Pinang, Malaysia. http://www-naweb.iaea.org/nafa/ipc/public/Area-wide-control_1-72-Front-Cover.pdf

Mumford, J. D. 1997. Economic feasibility studies for areawide control of fruit flies and codling moth. SAF/5/002-02-01, Joint FAO/IAEA Division, IAEA, Vienna, Austria. 31 pp.

Mumford, J. D. 2000. Economics of area-wide pest control, pp. 39-48. In K. H. Tan (ed.), Proceedings: Area-Wide Control of Fruit Flies and Other Insect Pests. International Conference on Area-Wide Control of Insect Pests, and the $5^{\text {th }}$ International Symposium on Fruit Flies of Economic Importance, 28 May-5 June 1998, Penang, Malaysia. Penerbit Universiti Sains Malaysia, Pulau Pinang, Malaysia. http://www-naweb.iaea.org/nafa/ipc/public/Area-wide-control_1-72-Front-Cover.pdf

Mumford, J. D. 2001. Environmental risk evaluation in quarantine decision making, pp. 353-383. In K. Anderson, C. McRae and D. Wilson (eds.), The economics of quarantine and the SPS agreement. Centre for International Economic Studies, Adelaide, and AFFA Biosecurity Australia, Canberra, Australia.

Mumford, J. D., and J. D. Knight. 1996. Economic analysis of alternatives of codling moth control. SYR/5/011/03, Joint FAO/IAEA Division, IAEA, Vienna, Austria. 34 pp.

Mumford, J. D., and A. Larcher Carvalho. 2001. Analise custo/benficio do programa de luta autocida contra a mosca-do-Mediterraneo, pp.78-90. In J. Passos de Carvalho (ed.), Caracterzacao da problematica da mosca-do-Mediterraneo, Ceratitis capitata (Wied.), visando a aplicacao da luta autocida no Algarve. Direccao Regional de Agricultura do Algarve, Faro, Portugal. 106 pp.

Mumford, J. D., A. Driouchi, W. Enkerlin, G. A. Carlson, and E. J. Buycx. 1995. Economic evaluation of damage caused by, and methods of control of, the Mediterranean fruit fly in the Maghreb. IAEA-TECDOC-830 (ISSN 1011-4289), International Atomic Energy Agency, Vienna, Austria. 68 pp.

https:/www.iaea.org/publications/5476/economic-evaluation-of-damage-caused-by-and-methods-ofcontrol-of-the-mediterranean-fruit-fly-in-the-maghreb

Mumford, J. D., J. D. Knight, D. C. Cook, M. M. Quinlan, J. Pluske, and A. W. Leach. 2001. Benefit cost analysis of Mediterranean fruit fly management options in Western Australia. Imperial College London, Silwood Park, Ascot, UK. 53 pp.

(OAU) Organization of African Unity. 2000. Pan African Tsetse and Trypanosomosis Eradication Campaign (PATTEC). Nairobi, Kenya, 7-16 December 2000. 39 pp.

(OMB) Office of Management and Budget. 2015. Discount rates for cost-effectiveness, lease purchase, and related analyses. OMB Circular A-94, Appendix C. https:/www.federalregister.gov/documents/2015/01/29/2015-01616/discount-rates-for-costeffectiveness-analysis-of-federal-programs

Pereira, R., B. Yuval, P. Liedo, P. E. A. Teal, T. E. Shelly, D. O. McInnis, and J. Hendrichs. 2013. Improving sterile male performance in support of programmes integrating the sterile insect technique against fruit flies. Journal of Applied Entomology 137, Special Issue, Supplement s1: 178-190. http://onlinelibrary.wiley.com/doi/10.1111/j.1439-0418.2011.01664.x/abstract

Price, N. S., and I. Seeworoothun (eds.). 2000. Proceedings: Indian Ocean Commission Regional Fruit Fly Symposium, 5-9 June 2000, Flic en Flac, Mauritius. Indian Ocean Commission, Quatre Bornes, Mauritius. 232 pp.

(OKSIR) Okanagan-Kootenay Sterile Insect Release Program. 2020. https://www.oksir.org/

Smith, D. L., K. E. Battle, S. L. Hay, C. M. Barker, T. W. Scott, and F. E. McKenzie. 2012. Ross, Macdonald, and a theory for the dynamics and control of mosquito-transmitted pathogens. PLOS Pathogens 8(4): e1002588. https://doi.org/10.1371/journal.ppat.1002588

Stonehouse, J. M., J. D. Mumford, and G. Mustafa. 1998. Economic losses to tephritid fruit flies (Diptera: Tephritidae) in Pakistan. Crop Protection 17: 159-164. https://doi.org/10.1016/S0261-2194(97)00091-4

Tweddle, N., and R. J. Mahon. 2000. Insurance against an Old World screw-worm fly invasion of Australia, pp. 95-100. In K. H. Tan (ed.), Proceedings: Area-Wide Control of Fruit Flies and Other Insect Pests. International Conference on Area-Wide Control of Insect Pests, and the $5^{\text {th }}$ International Symposium on Fruit Flies of Economic Importance, 28 May-5 June 1998, Penang, Malaysia. Penerbit Universiti Sains Malaysia, Pulau Pinang, Malaysia. http://www-naweb.iaea.org/nafa/ipc/public/Area-wide-control_73-229.pdf

(UN) United Nations. 1997. Mediterranean fruit fly eradication in Chile. http://www.un.org/esa/earthsummit/iaea.htm 
(USDA) United States Department of Agriculture. 2014. Mediterranean fruit fly release program. 2014 Review of sterile insect release facilities. $30 \mathrm{pp}$.

https://www.aphis.usda.gov/plant_health/plant_pest_info/fruit_flies/downloads/2014-medfly-prpreview.pdf

Vo, T. T. 2000. Economic impact of eradicating the New World screw-worm (Cochliomyia hominivorax) from Jamaica, pp. 113-116. In K. H. Tan (ed.), Proceedings: Area-Wide Control of Fruit Flies and Other Insect Pests. International Conference on Area-Wide Control of Insect Pests, and the $5^{\text {th }}$ International Symposium on Fruit Flies of Economic Importance, 28 May-5 June 1998, Penang, Malaysia. Penerbit Universiti Sains Malaysia, Pulau Pinang, Malaysia. http://www-naweb.iaea.org/nafa/ipc/public/Area-wide-control_73-229.pdf

Vreysen, M. J. B., J. E. Carpenter, and F. Marec. 2010. Improvement of the sterile insect technique for codling moth Cydia pomonella (Linnaeus) (Lepidoptera Tortricidae) to facilitate expansion of field application. Journal of Applied Entomology 134: 165-181. http://onlinelibrary.wiley.com/doi/10.1111/j.1439-0418.2009.01430.x/abstract

Vreysen, M. J. B., K. Saleh, F. Mramba, A. Parker, U. Feldmann, V. A. Dyck, A. Msangi, and J. Bouyer. 2014. Sterile insects to enhance agricultural development: the case of sustainable tsetse eradication on Unguja Island, Zanzibar, using an area-wide integrated pest management approach. PLoS Neglected Tropical Diseases 8(5): e2857. http://dx.doi.org/10.1371/journal.pntd.0002857

Waage, J. K., J. D. Mumford, A. W. Leach, J. D. Knight, and M. M. Quinlan. 2007. Responsibility and cost-sharing in quarantine plant health. Department for Environment, Food and Rural Affairs, London, UK. $126 \mathrm{pp}$.

Wyss, J. H. 2000. Screw-worm eradication in the Americas - Overview, pp. 79-88. In K. H. Tan (ed.), Proceedings: Area-Wide Control of Fruit Flies and Other Insect Pests. International Conference on Area-Wide Control of Insect Pests, and the $5^{\text {th }}$ International Symposium on Fruit Flies of Economic Importance, 28 May-5 June 1998, Penang, Malaysia. Penerbit Universiti Sains Malaysia, Pulau Pinang, Malaysia.

http://www-naweb.iaea.org/nafa/ipc/public/Area-wide-control_73-229.pdf 